\title{
Moderating Effect of Employee Engagement on the Relationship between Personality Traits and Team Performance: A Study of Employees in Private Colleges in Oman
}

\author{
Ms. Faiza Amir ${ }^{1} \&$ Zaheer Ahmed Khan ${ }^{2}$ \\ ${ }^{1}$ Lecturer in Economics and Business Studies Department, Mazoon College Muscat Oman, Oman \\ ${ }^{2}$ Assistant Professor in Economics and Business Studies Department, Mazoon College Muscat Oman, Oman \\ Correspondence: Zaheer Ahmed Khan, Assistant Professor in Economics and Business Studies Department, \\ Mazoon College Muscat Oman, Oman. E-mail: zaheer.khan@mazcol.edu.om
}

Received: January 7, 2020

doi:10.5539/ijbm.v15n3p67
Accepted: February 5, $2020 \quad$ Online Published: February 17, 2020

URL: https://doi.org/10.5539/ijbm.v15n3p67

\begin{abstract}
This study examines the impact of the five-factor model of personality on team performance of teaching and administration staff in private colleges in Oman. The five-factor model consists of extroversion, agreeableness, conscientiousness, openness to experience and neuroticism. A field study had been conducted using a sample size of 130 employees in private colleges in Oman. Data was collected through a 36-item questionnaire through convenience sampling. As anticipated, the results are consistent with many previous searches presenting the relationship between agreeableness, conscientiousness, extroversion, and openness to experience on team performance is positive and significant while neuroticism has a negative relationship with team performance. Employee engagement does moderate the relationship between extroversion, agreeableness, conscientiousness, neuroticism and team performance. Employee engagement has a minor moderating effect on the relationship between openness to experience and team performance. The study has enlightened the reality of the relationship between personality traits and team performance with a clear understanding of the academic administration of colleges in Oman. Therefore, organizations should consider the personality traits of employees to improve the overall performance of teams. The sampling from a similar type of organization and exclusion of some of the contextual variables are limitations of this study that hinder generalization to other industries and contexts. This research recommends to include other variables such as gender difference and organizational culture through a cluster of organizations with a large sample that may add more to the validity of results for generalization.
\end{abstract}

Keywords: personality traits, team performance, employee engagement

\section{Introduction}

Personality is an important factor related to the prediction of performance. Certain instincts of individuals determine the personality through the way the person acts or reacts to the environment. Personality dimensions play an important part in team performance even for short-lived self-managed work teams. Personality, generalized self-efficacy \& team performance (Biswas, 2008) provides the relationship between big five factors of personality and generalized perceived efficacy with team performance. Personality is defined as:

"The coherent pattern of effect, cognition, and desires (goals) as they lead to behavior" (Revelle, 2013). "A dynamic organization, inside the person, of psychophysical systems that create the person's characteristic patterns of behavior, thought, and feelings" (Allport, 1961, p.28).

The survival of a business entity is a very pertinent question in the arena of global competition and performance is key to success. Performance differentiates one company from other and organizations want a maximum contribution from their employees. Pursuing with contemporary management approaches many organizations have recreated their work efficiency through teams in recent years (Barrick et.al 2007). The complex nature of modern management styles has much emphasized at the utilization of the teamwork as a necessity to stick and survive at the edge of competition. Team building is a scientific approach all members of a team are interconnected and mutually accountable for the results. Cognizance of that fact about the quality of collective performance will determine the success or failure of that team. Human resources of a company are a significant asset which is engaged in performance through their individual and team contribution. The synergy of the team 
in the group enhances overall performance.

This is evident from the literature that research on team performance in developed countries is much higher in cases. Whereas, in developing and underdeveloped countries this has not received adequate attention from researchers. The focus of researcher's in the context of Sultanate Oman have been on other dimensions of organizational performance. The impact of personality dimensions (Ocean Model) is not evident in published literature (Puente et al, 2016; Khan and Mashikhi, 2017). Therefore, the current study focuses to find the effects of personality traits on team performance by examining how agreeableness, conscientiousness, openness to experience, neuroticism, and extroversion affect the outcomes of the team. Basically, the study investigates the moderating impact of employee engagement on the relationship between personality traits and team performance to seek answers to the following research questions in case of private colleges in Oman.

1. Is there any relationship between personality traits and team performance?

2. To what extent agreeableness, conscientiousness, openness to experience, neuroticism and extroversion positively relate to the performance of the team?

3. How significantly big five personality traits have an impact on team performance?

4. How significantly employee engagement moderates the impact of personality traits on team performance? The study of the link between personality dimensions and productivity is valuable for managers and researchers. First, the concern of role-playing by employees will get the attention of HR managers, and they may pay high attention to attitude, motivation, and personality as the most important attributes when hiring employees. Secondly, the outcomes of the study offer an adequate foundation for strategy interventions related to the training and development of employees because certain personality traits are more shapeable than cognitive skills.

\section{Review of Literature}

\subsection{Team Performance and Personality}

Besides other factors personality composition of team members because cross-level interactions with individual-level traits impact performance. D'Innocenzo, Mathieu \& Kukenberger (2016) through a multi-level perspective analysis of personality and team performance have reported individual-level agreeableness and conscientiousness directly affect work behavior and ad have comparative effects between team members. Curşeu, et al. (2018) reported a nonlinear association between five personality dimensions and their contributions to teamwork. Extraversion is identified as the most consistent predictor of personality for positive interpersonal interaction in teamwork linking personal motivation to team process ( $\mathrm{Hu} \&$ Liden, 2015). Extreme conscientiousness, extraversion, and agreeableness have been reported as detrimental to team performance (McCord et al., 2014; Carter et al., 2014).

Ancona and Caldwell (1992) defined team performance as: "The extent to which a team is able to meet its output goals (e.g., quality, functionality, and reliability of outputs), the expectations of its members, or its cost and time objectives" Team performance is a system of the interrelationship between individuals and groups linked to a shared purpose, which team members strive to achieve collectively. Team performance correlates to collective intelligence affected by the traits of members Team composition and personality is described by multilevel constructs of traits and these traits exert influence attitudes and behaviors of members. Therefore, as predisposing factors, they affect team performance through individual-level behaviors (Kim et al., 2017). Job performance is positively influenced by conscientiousness, openness, and pleasantness of team traits. Work behavior has a vital role in team traits and performance and guides team selection as well. Personality relates to interpersonal knowledge interaction and influences performance regarding the team as a complex adaptive system (Yue, \& Dang, 2017).

\subsection{Personality Traits}

\subsubsection{Agreeableness}

Agreeableness is a major dimension in the Big Five structural model of personality and vital in motivation to maintain positive relations with others (Graziano \& Tobin, 2017). People's characteristics of patterns of thoughts, feelings, and behaviors are reflected by personality traits. Personality traits also imply consistency and stability in a person. Hence, people with the characteristics of agreeableness are flexible, good-natured, trusting, forgiving, cooperative, tolerant and soft-hearted. Highly agreeable individuals are conflict-averse and non-competitive. On the other hand, members with low agreeableness may be perceived as unfriendly and untrustworthy. Agreeableness is the team performance member likeability. These people are based on liking others and viewing them positively. The people with this trait are helpful, generous, friendly, considerate and empathetic. The people with high agreeableness can more easily control their negative emotions (Jensen-Campbell, Knack, \& 
Gomez, 2010). Extrovert people are friendly, energetic, warm, assertive, social, outspoken and talkative. They could enhance the performance of a team and can easily convey their ideas to their team members at low team conflicts. Researchers have found extraversion as a valid predictor of performance in jobs characterized by social interaction, such as sales personnel and managers (Wihler et al., 2017, Antoncic et al., 2018). Neuroticism is the extent to which a person experiences negative emotions like anger, anxiety, hostility, and depression.

\subsubsection{Consciousness}

Individuals with conscientiousness exhibit traits of self-control being capable of working strategically towards goals, and carrying out tasks. Personality attributes together with psychological characteristics have a link with personality traits, hence model and design skills are fundamental to activity accomplishment (Avci \& Aran, 2016). A person who shows the characteristics of conscientiousness is dependable, careful, responsible, well prepared, hardworking, persevering and achievement-oriented. Such individuals are involved in a tendency to stay focused on concrete, pragmatic and realistic solutions. People with the trait of conscientiousness are self-disciplined, responsible, organized and task-oriented. Hence, hey will perform well in teams because of their disciplined personality. Teams having more conscientious people will perform well because their members prefer to complete their tasks on time in an organized way. Therefore, individuals with higher conscientiousness are expected to engage in teamwork behaviors due to common goals and coordination on tasks. Task focus, achievement -orientation and productivity impose a structural impact on their work environment.

\subsubsection{Extraversion}

Extraversion is an important feature of personality as a functional driver of social mechanisms in a team linked to the intra-team process. Extravert people with this trait are friendly, energetic, warm, assertive and social. Extrovert people are outspoken and talkative (Borman \& Motowidlo, 1993). Therefore they are thought to be beneficial to enhance the performance of a team (Van Vianen \& De Dreu, 2001). They can easily convey their ideas to their team members and may have low team conflicts because they are naturally talkative, enthusiastic and sociable (Costa \& McCrae, 1992). The extraverted team members appreciate highly observable role in teams and perceived by others as dominant leaders rather than "good team players" (Ames \& Flynn, 2007).

\subsubsection{Openness to Experience}

Openness to experience refers to imaginative, sensitive, intellectual provocation and creativity (McCrae, \& Sutin, 2009). High in openness to experience team members are broadminded, willing to try new things and creative and are expected to have new ideas to find ways to solve problems. They embrace the changes easily and support an environment of learning in new ways. Therefore, these people will result in low conflict with team members. Openness is attributed to creative activities which also reflects in self-reported behavior and expression and emotion regulation ability predict creativity in individuals who are relatively high in openness. (Ivcevic \& Mayer, 2009; Ivcevic \& Brackett, 2015). Based on the divergence of thoughts and general cognitive ability openness helps to the creativeness of thoughts (Kaufman et al., 2016). Sweeny et al. (2020) revealed that stressful experiences improve the degree of control that enhances the role of emotion-relevant traits in multicultural experiences and divergent thinking.

\subsubsection{Neuroticism}

Neuroticism represents individual differences in adjustment and emotional stability. Neurotic people tend to experience negative emotions, impulsiveness, depression, and anxiety (Zhao \& Seibert, 2006). Highly neurotic people tend to be more emotionally unstable by harboring: anxiety, anger, and depression. Therefore, such people perform poorly in teams due to their unstable nature. Neuroticism is a global indicator of maladaptive functionality and poor organizational citizenship behavior, hence neurotic individuals are ill-equipped to hold importance in matters of advice and friendship when working in teams (Fang et al., 2015; Ohana, 2016). Neuroticism is the extent to which a person experiences negative emotions like anger, anxiety, hostility, and depression. It represents the individual differences in personalities. Neuroticism represents individual differences in adjustment and emotional stability. It tends to experience negative emotions, impulsiveness, depression, and anxiety (Zhao \& Seibert 2006). The people, high in neuroticism tend to be more emotionally unstable having anxiety, anger, and depression. An emotionally unstable nature hinders teamwork performance of people with high in neuroticism. The higher level of neuroticism is associated with larger exposure and reactivity to stressors and a person with high neuroticism expresses a "hyper-reactivity" to stressors (Mroczek \& Almeida, 2004). Neuroticism leads to negative emotional reactions which may lead to tendencies of contradictory behavior (Leki, \& Wilkowski, 2017). 


\subsubsection{Employee Engagement}

Engagement is the attentiveness of employees to their work; deep and emotional connection towards their workplace. Khan (2017) argued that employees choose to invest themselves authentically and fully based on their experience in a working environment and viewed role engagement as the cognitive, emotional and physical expression of the authentic self at a work. A multilevel analysis by Mäkikangas (2016) revealed that team and individual engagement have an association with team performance. Inceoglu and Warr (2011) have highlighted the achievement orientation facet of conscientiousness as the strongest predictor of engagement. Similarly, conscientious employees exhibit high levels of work engagement (Halbesleben et al., 2009). Therefore, employees with high agreeableness tend to be more engaged compared to those with low on agreeableness.

\subsection{Theoretical Framework and Hypotheses}

The personality theory has been growing for decades (Norman, 1967; Goldberg, 1990) and a significant body of literature has supported a five-factor model of personality. The Big Five personality traits have substantial heritable components explaining 40-60\% of the variance (Bouchard, 1994).Recent researchers (Klotz \& Neubaum, 2016; Hu \& Judge, 2017; Prewett et al., 2018) have reported a positive correlation between dimensions of personality and performance. Multi-level constructs describe personality composition and team performance. An individual-level traits combination produces team-level performance. Conversely, top to the down influence of team level characteristics influences the behavior and individuals. Theoretical models (Le Pine et al., 2011; Salas et al., 2014: Loughry et al., 2007) have conceptualized the interaction of personality dimensions and team performance focusing on the aggregation of individual personality traits on team performance. Personality interactions affect the team performance, in that extroversion and agreeableness are interpersonal traits and consciousness is a task-related trait (Gonzalez-Mulé et al., 2014) and influence teamwork through cooperative norms and task engagement. Researchers (Lievens \& Sackett, 2012; Ohland, M et al., 2012) have reported a high correlation between involvement in interpersonal interaction and individuals' contribution to the task.

Big-five personality traits predict subjective well-being. A higher level of subjective well-being is related to higher levels of extraversion, agreeableness, conscientiousness, and lower levels of neuroticism. Therefore, extraverted, agreeable, conscientious, and emotionally stable people have higher perceived well-being (Soto, 2015). Evidence from literature indicates that trait interactions among the Big Five provide precise understanding regarding personality, behavior and physiological health (Turiano et al., 2013). Extraversion as a personality trait is characterized by high levels of positive affect and sociability provocations (e.g., Gomez, Cooper, \& Gomez, 2000; Penley \& Tomaka, 2002; Lucas \& Baird, 2004). A recent study (Leger et al., 2016) found that people higher in openness, conscientiousness, extraversion, and emotional stability have less emotional reactions to stressful events. Therefore, based on evidence of the impact of personality traits and team performance this research proposes the following hypotheses.

H1: Agreeableness positively influences team performance.

H2: Conscientiousness positively influences team performance.

H3: Extroversion positively influences team performance.

H4: Neuroticism negatively influences team performance.

H5: Openness to experience positively influences team performance.

Exploring the link between personality and engagement (Schaufeli, Bakker, \& Salanova, 2006), defined as "a fulfilling work-related state of mind that is characterized by vigor, dedication, and absorption". Akhtar et al. (2015) identified that openness to experience, interpersonal sensitivity, ambition, extroversion, adjustment, and conscientiousness are predictors of engagement. Whereas, extroversion, openness, conscientiousness, and agreeableness as predictors of work engagement. Based on preliminary evidence from literature, high extroversion, agreeableness, openness, conscientiousness and low neuroticism relate to high levels of work engagement. Given this association, the role of employee engagement on the relationship between personality traits and performance is inevitable. Therefore, the moderating effect of employee engagement on the relationship between big -five personality traits and team performance is hypothesized as;

H6a: Employee engagement moderates the influence of agreeableness on team performance.

H6b: Employee engagement moderates the influence of conscientiousness on team performance.

H6c: Employee engagement moderates the influence of extroversion on team performance.

H6d: Employee engagement moderates the influence of neuroticism on team performance. 
H06e: Employee engagement moderates the influence of openness to experience on team performance.

\section{Method}

The research is a field study conducted in natural settings as the inductive and exploratory study developed around the core practices framework of the predictive model. The study is prognostic in nature using quantitative data to investigate the phenomenon explained in objectives. The convenience sampling was used to collect the data. A self-administered structured questionnaire containing 36 items measuring responses through five points Likert Scale was used to collect the data. Instrument items for personality were adapted from (John and Srivastava, 1999), for performance (Erdem, Ozen, \& Atsan, 2003) and for employee engagement (Khan's, 1990).

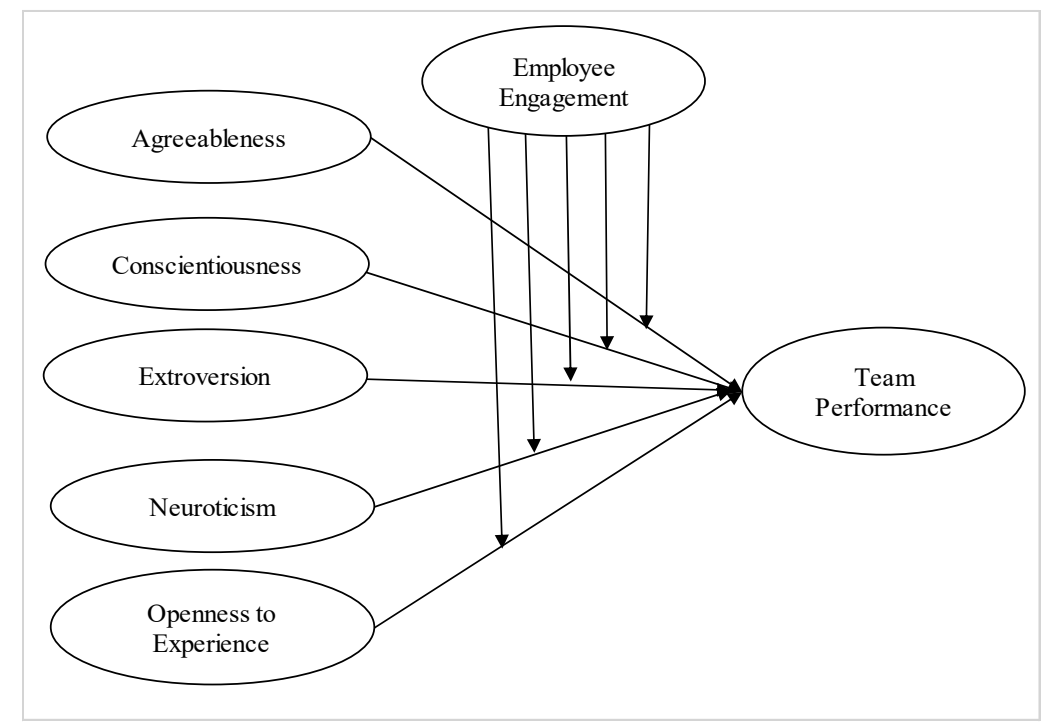

Figure 1. Conceptual framework

The target population consists of teaching and administrative staff working in private colleges in Oman. The participants were selected at convenience. A self-administered structured questionnaire measured through the Likert Scale was used to collect data. The response rate was $65 \%$ and a total of 200 questionnaires out of 130 were received completed by the respondents. In the sample of 130 respondents, there were $82 \%$ male and $18 \%$ female. Regarding the level of education: $31.53 \%$ hold Ph.D., $48.46 \%$ of the respondents have a master's degree, $20 \%$ bachelor. The sample comprised of different jobs: $29.2 \%$ of respondents were supervisory level, $61.8 \%$ teaching faculty and $9 \%$ administration departments. In order to examine the data and make a prediction of IVs on DV, both descriptive and inferential statistical tools (multiple and stepwise regression) were used.

\section{Results}

\subsection{Construct Model}

Prior to the assessment of the measurement model, EFA was performed using the Principal Component Analysis Method (PCA) in order to test loading of items and loadings above the cut-off value (i.e.0.50) were retained for further analysis (Hair et al., 2010). The partial least square (PLS) technique was used to assess the structural model in two stages (i.e. without the moderating variable and with moderating variable) to examine the relationship between the construct test hypotheses as well. 


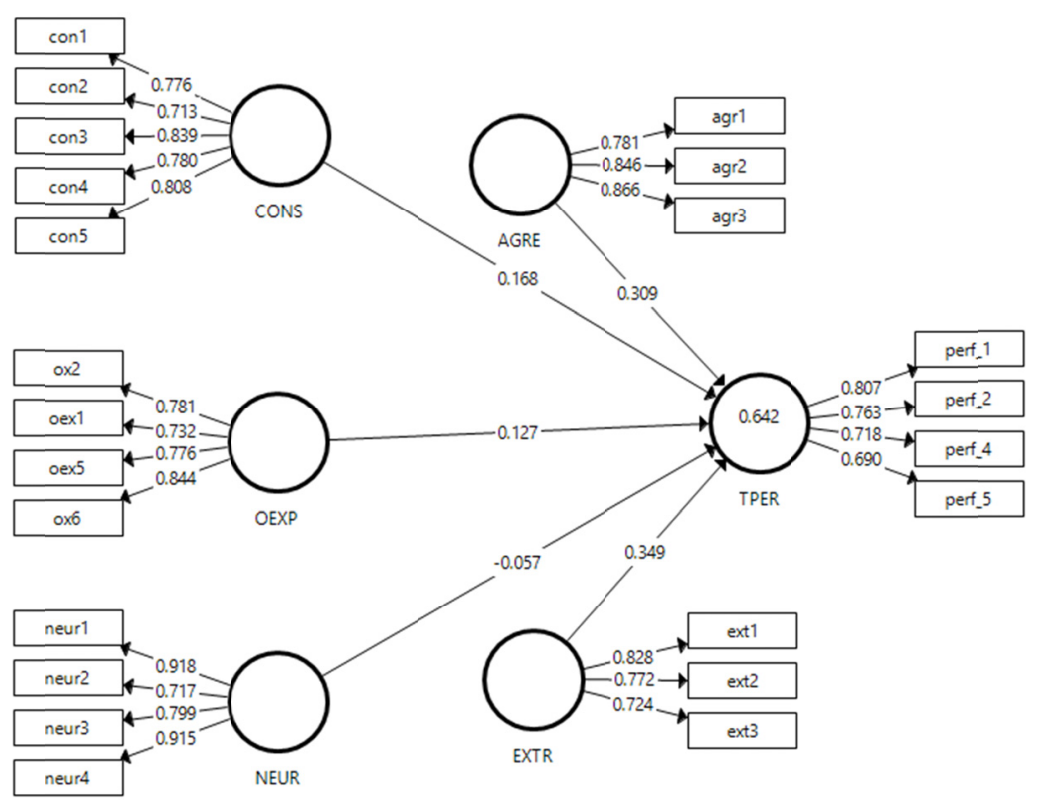

Figure 2. Construct model

The R-squared value 0.642 refers to that variation of the dependent variable is explained by the model is $64.2 \%$. The path coefficient values in the structural model are positive and imply the appositive relationship. The greatest impact on the team performance is from extroversion (factor 0.394), followed by agreeableness (factor $0.309)$ and then consciousness $(0.168)$. Openness to experience (factor 0.127$)$ neuroticism $(-0.057)$ has a negative relationship. Hence, four variables in the reflective model (AGRE, CONS, OEXP and EXTR) are statistically significant for the model.

\subsection{Measurement Model}

The other model was assessed by examining the reliability and validity of the measures representing constructs (Chin, 2010). Loadings more than recommended by Hair et al., (2010), the value of 0.700 were retained. Cronbach's alpha and composite reliability (CR) assesses the reliability of the model, while the validity assessed by using the average variance extracted (AVE). As shown in Table 1, the average variance extracted (AVE) for each construct above the recommended threshold 0.50 (Fornell and Larker, 1981). None of the Chronbach Alpha values are less than 0.7 and the model has a high level of reliability. All the constructs have an adequate convergent validity of high composite reliability (i.e. > 0.70) (Gerbing \& Andersen, 1988; Wright et al., 2010). 
Table 1. Construct reliability and validity

\begin{tabular}{|c|c|c|c|c|c|}
\hline Factor & Items & Loadings & Cronbach's Alpha & Composite Reliability & Average Variance Extracted (AVE) \\
\hline \multirow{3}{*}{ Agreeableness } & agr1 & 0.781 & \multirow{3}{*}{0.776} & \multirow{3}{*}{0.871} & \multirow{3}{*}{0.692} \\
\hline & agr2 & 0.846 & & & \\
\hline & agr3 & 0.866 & & & \\
\hline \multirow{5}{*}{ Consciousness } & con1 & 0.776 & \multirow{5}{*}{0.844} & \multirow{5}{*}{0.888} & \multirow{5}{*}{0.615} \\
\hline & $\operatorname{con} 2$ & 0.713 & & & \\
\hline & $\operatorname{con} 3$ & 0.839 & & & \\
\hline & $\operatorname{con} 4$ & 0.780 & & & \\
\hline & $\operatorname{con} 5$ & 0.808 & & & \\
\hline \multirow{3}{*}{ Extroversion } & ext1 & 0.828 & \multirow{3}{*}{0.669} & \multirow{3}{*}{0.819} & \multirow{3}{*}{0.602} \\
\hline & ext2 & 0.772 & & & \\
\hline & ext3 & 0.724 & & & \\
\hline \multirow{4}{*}{ Neuroticism } & neur1 & 0.918 & \multirow{4}{*}{0.858} & \multirow{4}{*}{0.906} & \multirow{4}{*}{0.708} \\
\hline & neur2 & 0.717 & & & \\
\hline & neur3 & 0.799 & & & \\
\hline & neur4 & 0.915 & & & \\
\hline \multirow{4}{*}{ Openness to Experience } & oex 1 & 0.732 & \multirow{4}{*}{0.791} & \multirow{4}{*}{0.864} & \multirow{4}{*}{0.615} \\
\hline & oex 5 & 0.776 & & & \\
\hline & oex2 & 0.781 & & & \\
\hline & oex6 & 0.844 & & & \\
\hline \multirow{4}{*}{ Performance } & perf_1 & 0.807 & \multirow{4}{*}{0.734} & \multirow{4}{*}{0.833} & \multirow{4}{*}{0.556} \\
\hline & perf_2 & 0.763 & & & \\
\hline & perf_4 & 0.718 & & & \\
\hline & perf_5 & 0.690 & & & \\
\hline
\end{tabular}

The discriminate validity explains the extent of how much measures are unique and not reflecting other variables (Peter and Churchill 1986). Table 2 shows AVE and cross factor loading where all items have a higher loading on their corresponding construct and AVE for each latent factor is exceeding the respective squared correlation between factors. The discriminant validity (Fornell and Larcker, 1981) confirmed adequate reliability, convergent validity, and discriminant validity for verification of the research model.

Table 2. Fornell-Larcker criterion

\begin{tabular}{llllllll}
\hline & AGRE & CONS & EXTR & NEUR & OEXP & TPER & AVE \\
\hline AGRE & 0.832 & & & & & & 0.692 \\
CONS & 0.650 & 0.784 & & & & & 0.615 \\
EXTR & 0.723 & 0.767 & 0.776 & & & & 0.602 \\
NEUR & 0.691 & 0.759 & 0.771 & 0.842 & & & 0.708 \\
OEXP & 0.652 & 0.741 & 0.736 & 0.731 & 0.784 & & 0.615 \\
TPER & 0.715 & 0.686 & 0.745 & 0.697 & 0.669 & 0.746 & 0.556 \\
\hline
\end{tabular}

\subsection{Estimation of Path Coefficients ( $\beta$ ) and T-Statistics}

The significance of path coefficients can be seen by calculating t-values through a bootstrapping procedure of 5000 samples which provided the basis for hypotheses testing. R-square $(0.642)$ indicated a good power of the model for prediction and path coefficients reflect the strength of the relationship between exogenous and endogenous variables. 
Table 3. Estimation of Path Coefficients $(\beta)$ and T-statistics

\begin{tabular}{lllccc}
\hline \multicolumn{2}{c}{ Hypothesized Relationship } & Std. Beta & T Statistics & p- Values & Decision \\
\hline H1 & AGRE -> TPER & 0.309 & 5.055 & $0.000^{*}$ & Supported \\
H2 & CONS -> TPER & 0.168 & 2.406 & $0.016^{*}$ & Supported \\
H3 & EXTR -> TPER & 0.349 & 3.807 & $0.000^{*}$ & Supported \\
H4 & NEUR -> TPER & -0.057 & 0.707 & 0.480 & Not Supported \\
H5 & OEXP -> TPER & 0.127 & 2.325 & $0.020^{*}$ & Supported \\
\hline
\end{tabular}

Notes. *significant at $95 \% \mathrm{CI}$

AGRE: Agreeableness, CONS: Consciousness, EENG: Employee Engagement, EXTR: Extroversion

NEUR: Neuroticism, OEXP:

Openness to Experience, TPER: Team performance

As shown in table 3 , the results predicted that the agreeableness $(\beta=0.309, T=5.05, p<0.050)$ positively influences team performance to accept H1.Consciousness significantly influenced team performance $(\beta=0.168$, $\mathrm{T}=2.406, \mathrm{p}<0.050)$ and $\mathrm{H} 2$ is accepted. The influence of extroversion on team performance is significantly positive $(\beta=0.349, \mathrm{~T}=3.807, \mathrm{p}<0.05)$ and supporting $\mathrm{H} 3$. The influence of neuroticism on team performance is negative $(\beta=-0.057, \mathrm{~T}=0.707, \mathrm{p}>0.05)$, but $\mathrm{H} 4$ is not supported. The effect of openness to experience $(\beta=$ $0.127, \mathrm{~T}=2.325, \mathrm{p}<0.05)$ on team performance is significant and H5 is supported.

The moderating effect of employee engagement was examined through bootstrapping of 5000 samples for prediction of product interaction of employee engagement (EENG) with performance. The table 4 (model 2) provided empirical support that employee engagement was not a moderator on the relationship of predictors (AGRE, CONS, EXTR, and NEU) and the outcome variable (TPER). Therefore H6a, H6b, H6c, and H6d are not supported.

Table 4. Moderating effect

\begin{tabular}{|c|c|c|c|c|c|c|c|}
\hline \multirow{2}{*}{\multicolumn{2}{|c|}{ Hypothesized Relationship }} & \multicolumn{3}{|l|}{ Model 1} & \multicolumn{3}{|l|}{ Model2 } \\
\hline & & St.Beta & p-value & & St.Beta & p-value & \\
\hline H6a & EENG*AGRE -> TPER & 0.309 & $0.000 *$ & \multirow{5}{*}{$\begin{array}{c}\mathrm{R}^{2} \\
0.642\end{array}$} & 0.047 & 0.512 & \multirow{6}{*}{$\begin{array}{c}\mathrm{R}^{2} \\
0.661\end{array}$} \\
\hline $\mathrm{H} 6 \mathrm{~b}$ & EENG*CONS -> TPER & 0.168 & $0.016^{*}$ & & 0.004 & 0.918 & \\
\hline H6c & EENG*EXTR -> TPER & 0.349 & $0.000 *$ & & 0.028 & 0.548 & \\
\hline H6d & EENG*NEU -> TPER & -0.057 & 0.480 & & -0.041 & 0.410 & \\
\hline H6e & EENG*OEXP -> TPER & 0.127 & $0.020 *$ & & 0.084 & 0.043 & \\
\hline \multicolumn{7}{|c|}{$\mathrm{R}^{2}$ Change $\Delta 0.012$} & \\
\hline
\end{tabular}

A slight moderating effect of employee engagement was found on the relationship between openness to experience (OEXP) and team performance to support H6e. As shown in figure 3, the moderating effect is positive but not significant enough to impact the strength of the relationship.

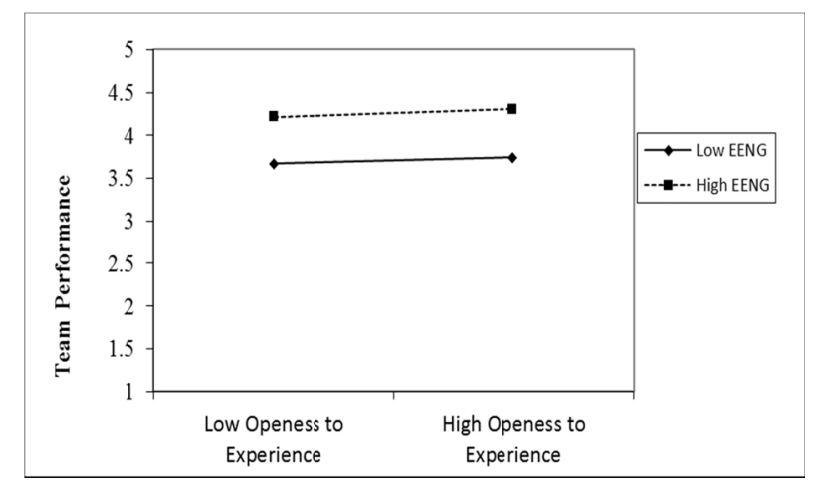

Figure 3. Moderating effect 


\section{Discussion}

The study has revealed that four (agreeableness, consciousness, extroversion, and openness to experience) Bigfive personality traits affect team performance significantly and neuroticism has an insignificant relationship with team performance. As anticipated, the results of the study support the existence of the positive impact of five personality traits on team performance except for neuroticism. The findings are consistent with (Barrick et al., 1998; Van Vianen \& De Dreu, 2001; Schippers, 2014) and confirm that higher levels of agreeableness, consciousness, extroversion, and openness to experience lead to higher team performance. Neuroticism has a negative but insignificant impact on team performance. This finding is consistent with (Kichuk \& Wiesner 1997; Barrick et.al. 2007; Zhao \& Seibert 2006). Highly neurotic people tend to be more emotionally unstable. Particularly in terms of anxiety, anger, and depression. Thus, do not operate well as a team player because of their instability. In the current scenario of private colleges in Oman neuroticism is not affecting team performance. On the other hand, the moderating effect of employee engagement is insignificant to the relationship between agreeableness, consciousness, extraversion, and neuroticism. The moderating effect of employee engagement on the relationship between openness to experience and team performance is positive but not very strong. The findings of this research have enlightened the reality of employee's contribution to teamwork as a general. Scholars (e.g. Tett \& Christiansen, 2007; Blickle, et al, 2013) support the importance of context to personality and performance relationship. In any case, regardless of the advantage of choosing the optimal blend of team members, this point has gotten little consideration in managerial decisions in some organizations. Overall, the study has one overarching message, it is that the impact of the personality traits on team performance cannot be seen apart from employee engagement. Personality has been distinguished as a conceivably supportive choice variable in the assurance of the ultimate group structure. They have argued that behavioral expression of the trait may differ from one to another situation. Before engaging in the generalization of the findings, certain limitations must be taken into account. In the pursuit of improving organizational output, the role of teams has become vital and a growing phenomenon. Managers can likewise utilize the Big Five traits on themselves to demonstrate to their followers how to amplify their qualities and learn from their weaknesses and continue to evaluate organizational behavior to drive the organization to success.

\section{Conclusion}

This research aimed at analyzing the effect of personality traits on team performance in private colleges in Oman. Besides, the study examined the moderating effect of employee engagement on the relationship between personality traits and team performance. The consistency of the results with previous studies confirmed that higher levels of agreeableness, consciousness, extroversion, and openness to experience lead to higher team performance. The moderating effect of employee engagement was not significant to the relationship between agreeableness, consciousness, extraversion, and neuroticism. Employee engagement moderates the relationship between openness to experience and team performance which is positive but not very strong. Before generalizing the results to other industries this is very important to consider that the results taken of this study are based on samples composed of only one segment of educational institutions. This research contributes to literary evidence based on empirical data in exploring the impact of personality traits on performance in private higher educational institutions in Oman. The absence of contextual variables is one of the limitations of the study. The outcomes of the current study merit further research on this topic with the large example size and incorporation of some contextual variables utilizing cluster sampling may lead to added validity of results for generalization.

\section{Acknowledgments}

This research has not been funded by any government or private institution. Both the authors have equal contribution in conducting this research.

\section{References}

Akhtar, R., Boustani, L., Tsivrikos, D., \& Chamorro-Premuzic, T. (2015). The engageable personality: Personality and trait EI as predictors of work engagement. Personality and Individual Differences, 73, 44-49.

Allport, G. W. (1961). Pattern and growth in personality.

Ames, D. R., \& Flynn, F. J. (2007). What breaks a leader: The curvilinear relation between assertiveness and leadership. Journal of Personality and Social Psychology, 92, 307-324.

Ancona, D. G., \& Caldwell, D. F. (1992). Demography and design: Predictors of new product team performance. Organization Science, 3(3), 321-341.

Antoncic, J. A., Antoncic, B., Grum, D. K., \& Ruzzier, M. (2018). The Big Five Personality Of The SME 
Manager And Their Company'S Performance. Journal of Developmental Entrepreneurship, 23(04).

Avci, U., \& Aran, O. (2016). Predicting the performance in decision-making tasks: From individual cues to group interaction. IEEE Transactions on Multimedia, 18(4), 643-658.

Barrick, M. R., Bradley, B. H., Kristof-Brown, A. L., \& Colbert, A. E. (2007). The moderating role of top management team interdependence: Implications for real teams and working groups. Academy of Management Journal, 50(3), 544-557.

Barrick, M. R., Stewart, G. L., Neubert, M. J., \& Mount, M. K. (1998). Relating member ability and personality to work-team processes and team effectiveness. Journal of applied psychology, 83(3), 377.

Biswas, S. N. (2008). Personality, generalized self-efficacy \& team performance: a study of rural development teams. Indian Journal of Industrial Relations, 234-247.

Blickle, G., Meurs, J. A., Wihler, A., Ewen, C., Plies, A., \& Günther, S. (2013). The interactive effects of conscientiousness, openness to experience, and political skill on job performance in complex jobs: The importance of context. Journal of Organizational Behavior, 34(8), 1145-1164.

Borman, W. C., \& Motowidlo, S. J. (1993). Expanding the criterion domain to include elements of contextual performance. In N. Schmitt, W. C. Borman, A. Howard, A. Kraut, D. Ilgen, B. Schneider, \& S. Zedeck (Eds.), Personnel selection in organizations (pp. 71-98). San Francisco: Jossey-Bass.

Bouchard, T. J. (1994). Genes, environment, and personality. Science-AAAS-Weekly Paper Edition, 264(5166), 1700-1701.

Carter, A. J., Marshall, H. H., Heinsohn, R., \& Cowlishaw, G. (2014). Personality predicts the propensity for social learning in a wild primate. PeerJ, 2, e283.

Chin, W. W. (2010). How to write up and report PLS analyses. In Handbook of partial least squares (pp. 655-690). Springer, Berlin, Heidelberg.

Costa Jr, P. T., \& McCrae, R. R. (2008). The Revised NEO Personality Inventory (NEO-PI-R).

Curşeu, P. L., Ilies, R., Vîrgă, D., Maricuţoiu, L., \& Sava, F. A. (2018). Personality characteristics that are valued in teams: Not always "more is better"? International Journal of Psychology.

D’Innocenzo, L., Mathieu, J. E., \& Kukenberger, M. R. (2016). A meta-analysis of different forms of shared leadership-team performance relations. Journal of Management, 42(7), 1964-1991.

Driskell, T., Driskell, J. E., \& Salas, E. (2014). Stress, performance, and decision making in organizations. Judgment and Decision Making At Work, 251-276.

Erdem, F., Ozen, J., \& Atsan, N. (2003). The relationship between trust and team performance. Work-study, 52(7), 337-340. Fang, R., Landis, B., Zhang, Z., Anderson, M. H., Shaw, J. D., \& Kilduff, M. (2015). Integrating personality and social networks: A meta-analysis of personality, network position, and work outcomes in organizations. Organization Science, 26, 1243-1260.

Fang, R., Landis, B., Zhang, Z., Anderson, M. H., Shaw, J. D., \& Kilduff, M. (2015). Integrating personality and social networks: A meta-analysis of personality, network position, and work outcomes in organizations. Organization Science, 26(4), 1243-1260.

Farrukh, M., Khan, A. A., Khan, M. S., Ramzani, S. R., \& Soladoye, B. S. A. (2017). Entrepreneurial intentions: the role of family factors, personality traits and self-efficacy. World Journal of Entrepreneurship, Management and Sustainable Development.

Fornell, C., \& Larcker, D. F. (1981). Structural equation models with unobservable variables and measurement error: Algebra and statistics.

Gerbing, D. W., \& Anderson, J. C. (1988). An updated paradigm for scale development incorporating unidimensionality and its assessment. Journal of marketing research, 25(2), 186-192.

Goldberg, L. R. (1990). An alternative" description of personality": the big-five factor structure. Journal of Personality and Social Psychology, 59(6), 1216.

Gomez, R., Gomez, A., \& Cooper, A. (2002). Neuroticism and extraversion as predictors of negative and positive emotional information processing: comparing Eysenck's, Gray's, and Newman's theories. European journal of personality, 16(5), 333-350.

Gonzalez-Mulé, E., DeGeest, D. S., McCormick, B. W., Seong, J. Y., \& Brown, K. G. (2014). Can we get some 
cooperation around here? The mediating role of group norms on the relationship between team personality and individual helping behaviors. Journal of Applied Psychology, 99(5), 988.

Graziano, W. G., \& Tobin, R. M. (2017). Agreeableness and the five-factor model. The Oxford Handbook of the Five-Factor Model, 105-132.

Hair, J. F. (2010). Multivariate data analysis, 7.

Halbesleben, J. R. B., Harvey, J., \& Bolino, M. C. (2009). Too engaged? Conservation of resources view of the relationship between work engagement and work interference with family. Journal of Applied Psychology, 94, 1452-1465.

Hu, J., \& Judge, T. A. (2017). Leader-team complementarity: Exploring the interactive effects of leader personality traits and team power distance values on team processes and performance. Journal of Applied Psychology, 102(6), 935.

$\mathrm{Hu}$, J., \& Liden, R. C. (2015). Making a difference in the teamwork: Linking team prosocial motivation to team processes and effectiveness. Academy of Management Journal, 58(4), 1102-1127.

Inceoglu, I., \& Warr, P. (2011). Personality and job engagement. Journal of Personnel Psychology, 4, 177-181.

Ivcevic, Z., \& Brackett, M. A. (2015). Predicting creativity: Interactive effects of openness to experience and emotion regulation ability. Psychology of Aesthetics, Creativity, and the Arts, 9(4), 480.

Ivcevic, Z., \& Mayer, J. D. (2009). Mapping dimensions of creativity in the life-space. Creativity Research Journal, 21, 152-165. http://dx.doi.org/10.1080/10400410902855259

Jensen-Campbell, L. A., Knack, J. M., \& Gomez, H. L. (2010). The psychology of nice people. Social and Personality Psychology Compass, 4(11), 1042-1056.

John, O. P., \& Srivastava, S. (1999). The Big Five trait taxonomy: History, measurement, and theoretical perspectives. Handbook of personality: Theory and research, 2(1999), 102-138.

Kahn, W.A. (1990). Psychological conditions of personal engagement and disengagement at work. Academy of Management Journal, 33, 692-724.

Kaufman, S. B., Quilty, L. C., Grazioplene, R. G., Hirsh, J. B., Gray, J. R., Peterson, J. B., \& DeYoung, C. G. (2016). Openness to experience and intellect differentially predict creative achievement in the arts and sciences. Journal of personality, 84(2), 248-258. http://doi.org/10.1111/jopy.12156

Khan, S., \& Mashikhi, L. S. (2017). Impact of teamwork on employee's performance. International. Journal of Education and Social Science, 4(11), 14-22.

Kichuk, S. L., \& Wiesner, W. H. (1997). The big five personality factors and team performance: implications for selecting successful product design teams. Journal of Engineering and Technology Management, 14(3-4), $195-221$.

Kim, Y. J., Engel, D., Woolley, A. W., Lin, J. Y. T., McArthur, N., \& Malone, T. W. (2017, February). What makes a strong team?: Using collective intelligence to predict team performance in League of Legends. In Proceedings of the 2017 ACM Conference on Computer Supported Cooperative Work and Social Computing (pp. 2316-2329). ACM.

Klotz, A. C., \& Neubaum, D. O. (2016). Article commentary: Research on the dark side of personality traits in entrepreneurship: Observations from an organizational behavior perspective. Entrepreneurship Theory and Practice, 40(1), 7-17.

Leger, K. A., Charles, S. T., Turiano, N. A., \& Almeida, D. M. (2016). Personality and stressor-related affect. Journal of Personality and Social Psychology, 111(6), 917-928. https://doi.org/10.1037/pspp0000083

Leki, E. F., \& Wilkowski, B. M. (2017). Trait anger, neuroticism, and the hostile reaction to provocation: examining the hierarchical organization of affective traits in context. Motivation and Emotion, 41(6), 713-729.

LePine, J. A., Buckman, B. R., Crawford, E. R., \& Methot, J. R. (2011). A review of research on personality in teams: Accounting for pathways spanning levels of theory and analysis. Human Resource Management Review, 21(4), 311-330.

Lievens, F., \& Sackett, P. R. (2012). The validity of interpersonal skills assessment via situational judgment tests for predicting academic success and job performance. Journal of Applied Psychology, 97(2), 460. 
Lucas, R. E., \& Baird, B. M. (2004). Extraversion and emotional reactivity. Journal of Personality and Social Psychology, 86(3), 473.

Mäkikangas, A., Aunola, K., Seppälä, P., \& Hakanen, J. (2016). Work engagement-team performance relationship: shared job crafting as a moderator. Journal of Occupational and Organizational Psychology, 89(4), 772-790.

McCord, M. A., Joseph, D. L., \& Grijalva, E. (2014). Blinded by the light: The dark side of traditionally desirable personality traits. Industrial and Organizational Psychology, 7, 130-137.

McCrae, R. R., \& Sutin, A. R. (2009). Openness to experience. Handbook of Individual Differences in Social Behavior, 15, 257-273.

Mroczek, D. K., \& Almeida, D. M. (2004). The effect of daily stress, personality, and age on daily negative affect. Journal of Personality, 72(2), 355-378.

Norman, W. T. (1967). 2800 Personality Trait Descriptors--Normative Operating Characteristics for a University Population.

Ohana, M., \& Stinglhamber, F. (2019). Co-workers' voice climate and affective commitment towards the team: A test of mediation and moderation. Human Resource Management Journal, 29(3), 395-412.

Ohland, M. W., Loughry, M. L., Woehr, D. J., Bullard, L. G., Felder, R. M., Finelli, C. J., ... \& Schmucker, D. G. (2012). The comprehensive assessment of team member effectiveness: Development of a behaviorally anchored rating scale for self-and peer evaluation. Academy of Management Learning \& Education, 11(4), 609-630.

Peñacoba-Puente, C., Marín-Morales, D., Carmona-Monge, F. J., \& Velasco Furlong, L. (2016). Post-Partum Depression, Personality, and Cognitive-Emotional Factors: A Longitudinal Study on Spanish Pregnant Women. Health Care for Women International, 37(1), 97-117.

Penley, J. A., Tomaka, J., \& Wiebe, J. S. (2002). The association of coping with physical and psychological health outcomes: A meta-analytic review. Journal of Behavioral Medicine, 25(6), 551-603.

Peter, J. P., \& Churchill Jr, G. A. (1986). Relationships among research design choices and psychometric properties of rating scales: A meta-analysis. Journal of Marketing Research, 23(1), 1-10.

Prewett, M. S., Brown, M. I., Goswami, A., \& Christiansen, N. D. (2018). Effects of team personality composition on member performance: A multilevel perspective. Group \& Organization Management, 43(2), 316-348.

Revelle, W., \& Wilt, J. (2013). The general factor of personality: A general critique. Journal of Research in Personality, 47(5), 493-504.

Schaufeli, W. B., Bakker, A. B., \& Salanova, M. (2006). The measurement of work engagement with a short questionnaire a cross-national study. Educational and Psychological Measurement, 66(4), 701-716.

Schippers, M. C. (2014). Social loafing tendencies and team performance: The compensating effect of agreeableness and conscientiousness. Academy of Management Learning \& Education, 13(1), 62-81.

Soto, C. J. (2015). Is happiness good for your personality? Concurrent and prospective relations of the big five with subjective well-being. Journal of personality, 83(1), 45-55.

Sweeny, K., Howell, J. L., \& Kwan, V. W. (2020). Losing control: Comparing the role of personality during two types of stressful life experiences. Personality and Individual Differences, 156, 109771

Tett, R. P., \& Christiansen, N. D. (2007). Personality tests at the crossroads: A response to Morgeson, Campion, Dipboye, Hollenbeck, Murphy, and Schmitt (2007). Personnel Psychology, 60(4), 967-993.

Turiano, N. A., Mroczek, D. K., Moynihan, J., \& Chapman, B. P. (2013). Big 5 personality traits and interleukin-6: Evidence for "healthy Neuroticism" in a US population sample. Brain, Behavior, and Immunity, 28, 83-89.

Van Vianen, A. E. M., \& De Dreu, C. K. W. (2001). Personality in teams: Its relations to social cohesion, task cohesion, and team performance. European Journal of Work and Organizational Psychology, 10, 97-120.

Van Vianen, A. E., \& De Dreu, C. K. (2001). Personality in teams: Its relationship to social cohesion, task cohesion, and team performance. European Journal of Work and Organizational Psychology, 10(2), 97-120.

Wihler, A., Meurs, J. A., Momm, T. D., John, J., \& Blickle, G. (2017). Conscientiousness, extraversion, and field 
sales performance: Combining narrow personality, social skill, emotional stability, and nonlinearity. Personality and Individual Differences, 104, 291-296.

Wright, R. T., Campbell, D. E., Thatcher, J. B., \& Roberts, N. H. (2012). Operationalizing Multidimensional Constructs in Structural Equation Modeling: Recommendations for IS Research. CAIS, 30(23), 367-412.

Yue, X., \& Dang, Y. (2017). The Effect of Personality on Team Performance: An Interpersonal Knowledge Interaction Perspective. In the 2017 IEEE International Conference on Software Quality, Reliability and Security Companion (QRS-C) (pp. 449-455). IEEE. https://doi.org/10.1109/QRS-C.2017.79

Zhao, H., \& Seibert, S. E. (2006). The big five personality dimensions and entrepreneurial status: A meta-analytical review. Journal of Applied Psychology, 91(2), 259.

\section{Copyrights}

Copyright for this article is retained by the author(s), with first publication rights granted to the journal.

This is an open-access article distributed under the terms and conditions of the Creative Commons Attribution license (http://creativecommons.org/licenses/by/4.0/). 